\title{
ESTIMATION OF EVAPOTRANSPIRATION BASED ON SURFACE ENERGY BALANCE ALGORITHM FOR LAND (SEBAL) USING LANDSAT 8 AND MODIS IMAGES
}

\author{
NOURI, H..$^{*}$ - FARAMARZI, M. ${ }^{2}-$ SOBHANI, B. ${ }^{3}-$ SADEGHI, S. H. ${ }^{2}$ \\ ${ }^{I}$ Department of Watershed Management and Research Institute of Grape and Raisin, \\ University of Malayer, Hamadan, Iran \\ ${ }^{2}$ Research Institute of Grape and Raisin, University of Malayer, Hamadan, Iran \\ ${ }^{3}$ Department of Geography, University of Mohaghegh Ardabili, Ardabil, Iran \\ *Corresponding author \\ e-mail: Hamidwatershed@yahoo.com \\ (Received $20^{\text {th }}$ Aug 2016; accepted $18^{\text {th }}$ Oct 2017)
}

\begin{abstract}
The aim of this study was to determine the accuracy estimation of actual evapotranspiration by using Surface Energy Balance Algorithm for Land (SEBAL) in comparison with FAO-Penman-Monteith method in Landsat and MODIS images in Malayer County of Iran. In this study, Landsat 8 and MODIS images of 2013 were used. Result showed that there are not many differences between SEBAL and FAOPenman-Monteith methods in estimation of evapotranspiration. According to the aim of the study, result showed that MODIS sensor with high accuracy have calculated evapotranspiration more accurately than Landsat 8 by RMSE $=1.004$ and MBE $=0.0033$ respectively in surface temperature estimation which has great effect on estimation of the net radiation flux, soil heat flux and the sensible heat flux. On the other hand, according to low spatial resolution of MODIS sensor, we can conclude that this sensor has less value for zoning of evapotranspiration than Landsat 8 image according to the area topography and heterogeneous land uses.
\end{abstract}

Keywords: evapotranspiration, remote sensing, SEBAL, Malayer city, MODIS, Landsat 8

\section{Introduction}

Evapotranspiration (ET) is an important component of water balance in arid and semi-arid areas and accurate estimation of ET is significantly important for optimum management of water resources (Sepaskhah, 1982). Hasheminia (1999) reported, 70 $\%$ of precipitation returns to the atmosphere through ET. He also cited in arid areas it is about $90 \%$. According to his output, water shortage problem has been widespread in many parts of the world which has brought about conflict over water in the near future. It seems that limitation of water resources and uneconomical uses of water are the main factors that limit the development of agriculture and increase food production in Iran (Akbari, 2004). On the other hand, ET plays significant role in the world's climate through hydrologic cycle. ET estimation has an important utilization on runoff prediction, product performance prediction, land use design, design of irrigation channels, water distribution constructions and it is also effective on natural disasters like drought (Ogawa et al., 1999; Bastiaanssen, 2000; Norman et al., 1995). Many methods have been developed for calculating ET in different geographical and climatic conditions by using meteorological data. These methods often use point (data) measurement for ET estimation, so they are appropriate for local area and they are not expendable to large basins because of dynamic nature and regional changes of 
ET (Li and Lyons, 1999; 2002). Development of remote sensing technology provides possibility of actual ET and potential ET estimation in a wide scale. In many researches satellite images were used to estimate actual ET and temporal and spatial distribution. Remote sensing is able to estimate ET also it can examine spatial distribution, because it can extract parameters such as surface temperature, albedo coefficient and vegetation index which is compatible with the environment and it is economically affordable (Norman et al., 1995). This distribution is important for management at the macro level. In the irrigation conference which was held by Food and Agriculture Organization (FAO) and International Commission on Irrigation and Drainage (ICID) and World Meteorological Organization (WMO) in cooperation in 1990 for investigating FAO methods and presenting an accurate method, FAOPenman-Monteith method proposed as a standard method for ET estimation (Allen et al., 1998). ICID and FAO proposed FAO-Penman-Monteith method as a standard method for ET calculation via climate data (Hargreaves, 1994). Heretofore, the multiple algorithms have been provided to estimate ET using remote sensing data. Thereby, the methods based on energy balance are divided into single-source and two-source models. Single-source models consider soil and plant as one source named "Big-Leaf" and they only use an aerodynamic resistance in water-heat transition process (Nishida et al., 2003). In these models, it is assumed that the entire affected surface receives the same temperature and humidity. Unlike single-source models, two-source models by separation of soil and plants in all modeling process use several distinct aerodynamic resistances for soil and plant (Huntingford et al., 2000). Among the popular models in single-source base, we can mention Surface Energy Balance for Land (SEBAL), Mapping Evapotranspiration at High Resolution with Internalized Calibration (METRIC) and Surface Energy Balance System (SEBS) (Bastiaanssen et al., 1998; Su, 2002; Allen et al., 2007; Ogawa et al., 1999). The models such as TSEB and STSEB are two-source models (Norman et al., 1995; Sánchez et al., 2008).

\section{Review of literature}

The SEBAL algorithm was used with different sensor images in multiple parts of the world and it provided acceptable results. The old SEBAL model with METRIC in Idaho and their output results were compared which had a good agreement with lysimeter data (Tasumi et al., 2005). In another study daily ET amounts with lysimeter data by using Landsat images and METRIC model were compared and error less than $28 \%$ was reported (Chavez et al., 2007). Estimation of ET by using Landsat images and energy balance METRIC model in Brazil had highlighted the model performance of water consumption estimation and improved water management in semi-arid and irrigated area in northeast of Brazil (Folhes et al., 2009). Evapotranspiration by using SEBAL algorithm and water balance model was calculated and results were compared, correlation by $70 \%$ was reported (Mutiga et al., 2010). Useful results were reported about using Landsat images and SEBAL algorithm for actual ET estimation in multiple land uses of Nansi Lake basin, China (Sun et al., 2011). Surface temperature, net radiation, soil heat flux and hourly ET amounts were calculated by using SEBAL algorithm and 16 TM images were used in Texas plain. Output results were compared with measured values of 4 lysimeters which in cotton planted in two modes: irrigated and under water stress. Results 
showed high accuracy of output results (Colaizzi et al., 2011). Different methods of ET estimation based on remote sensing data were investigated and results indicated that remote sensing methods have average accuracy for ET estimation (Raghuveer et al., 2011). Variable ET on the agriculture land, water body, forests and grasslands, are justifiable with different amount of ET (Yuting et al., 2012). Measured ET and other SEBAL components with measured field data through 4 accurate weighty lysimeters in two areas wet and dry farming were compared and acceptable results by using SEBAL were emphasized (Paul et al., 2013). Actual ET of pistachio in Ardakan, Yazd, by using 12 MODIS images and SEBAL algorithm were calculated. Results showed that average actual ET of pistachio is $1123 \mathrm{~mm}$ in desired year during a complete grow season which is much less than the amount of water consumption (Dasturani et al., 2012). Estimation and comparison of ET by using SEBAL algorithm, MODIS and Landsat 7 images were done and it was concluded that TM sensor image accuracy was about two and a half times more than MODIS (Simaie et al., 2013).

Although a huge number of studies have used different algorithms including SEBAL and multiple satellite images such as MODIS and Landsat. Over two decades studies were done about this issue, it is necessary to study different climate and weather for an accurate evaluation of ET based on these models and satellite images. Whereas, these models are experimental and they use a set of methods and experimental equations, they have to be calibrated for regional conditions. In the present study, actual ET have been estimated in Malayer city which has heterogeneous land uses such as range, residential, agricultural land (wet and dry), water bodies and so on. It should be mentioned that there is no record of any study using MODIS, Landsat or even other remote sensing images such as SEBAL or other models about ET estimation in the study area. However, most previous studies considered ET estimation in agricultural areas, either in an area with different land uses or new Landsat 8 satellite image, but the present study with an emphasis on performance of SEBAL, MODIS and Landsat 8 sensors have been investigated in a heterogeneous area.

\section{Material and methods}

Malayer city in Iran has an area of $3208 \mathrm{~km}^{2}$ which includes $16.9 \%$ of Hamadan province (Fig. 1). Elevation changes between 1617 and $3345 \mathrm{~m}$ (Fig. 1, digital elevation model is shown). The average amount of annual precipitation ranges is between 250 and $327 \mathrm{~mm}$ based on elevation gradient and extracted precipitation from whole city stations and neighborhood stations (Nahavand, Toiserkan, Hamadan Airport, Nouzhe, Arak, Kangavar and Borojerd) in a 17 years period (1995 to 2012). The amount of 24 hourly potential ET has been recorded by $7.58 \mathrm{~mm}$ averagely in Malayer station in May. Lysimeter data is usually used in different remote sensing studies for ET estimation. According to lack of lysimeter station in Malayer, synoptic station which records temperature, precipitation and evaporation are used as observed station to control output results (Fig. 1). Hourly data of 13 May 2012 at the same time with time recording of MODIS and Landsat 8 images were used by FAO-Penman-Montieth. Since the amount of precipitation and agriculture lands have been affected by water scarcity, thereby water consumption can be managed through ET estimation to reach a high efficiency. 


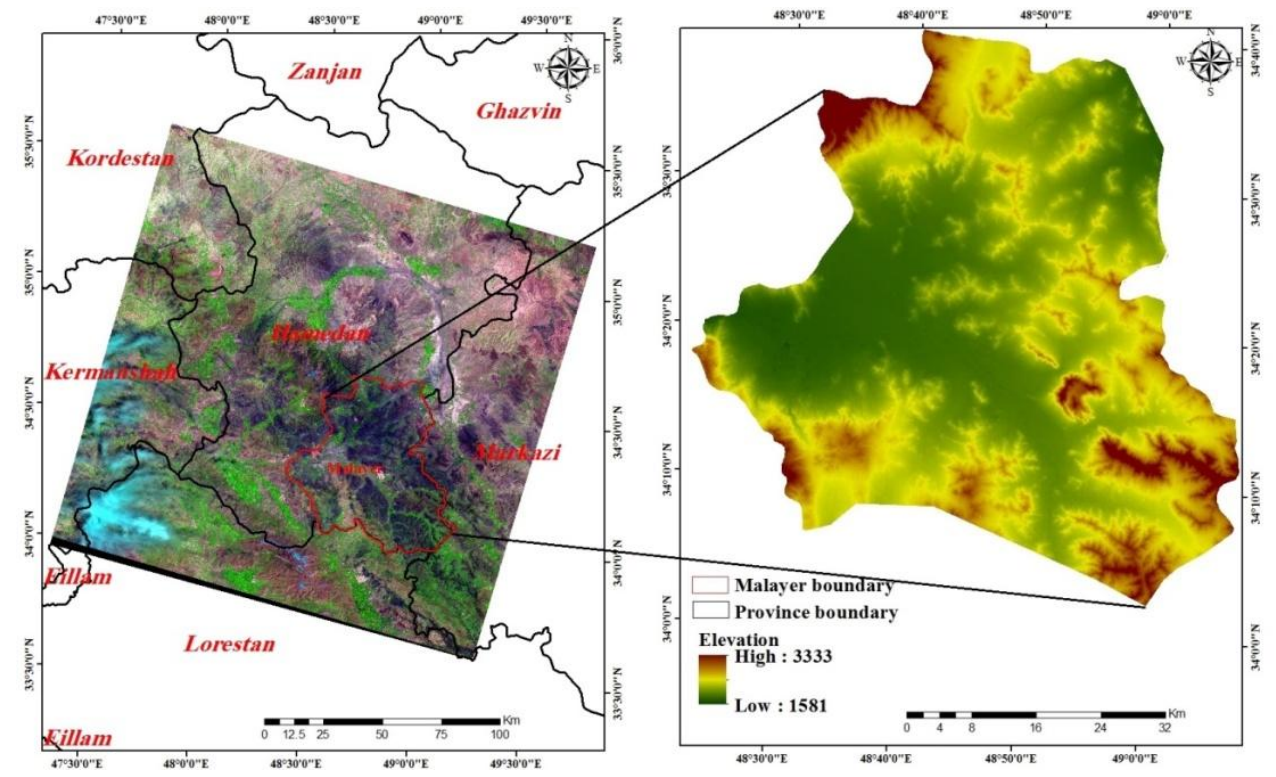

Figure 1. Geographical location of study area in Hamadan province

\section{Image selection, preparation and preprocessing}

One of the suitable images that are used around the world is free MODIS image. New free Landsat 8 images (OLI sensor) are one of the new feature in this case. Another point that should be mentioned is calibration of different images especially cheap images to local condition. Although MODIS image had been used in around of the world and also Iran, but these images and different algorithm including SEBAL are in the stage of development. Furthermore, significant research does not fulfillment in the field of use or calibration of different images including MODIS and Landsat 8 (OLI) images in Hamadan province which has distinct vegetation and climatic condition. In the present study images which have been selected are MODIS and Landsat 8 images for comparing factors including temporal condition (spring), desirable quality and lack of cloud cover spots. Although, the selected images were Level-II and they do not need geometric correction, but they were controlled with 10 ground control point (GCP) of GPS before using. Images did not need atmospheric correction because there was no atmospheric turbulence and they were one-temporal interpretation (Song et al., 2001). Table 1 presents used images properties.

Table 1. Properties of selected OLI image (Official Landsat 8 Site, 2013) and MODIS image

\begin{tabular}{|c|c|c|}
\hline MODIS & Landsat OLI & Image \\
\hline $05 / 14 / 2013$ & $05 / 14 / 2013$ & Data catch \\
$64-95$ & $125.471-128.2050$ & Sun azimuth angle \\
$36(9$ reflective, 17 thermal $)$ & $11(9$ reflective, 2 thermal $)$ & Number band \\
$250,500 \& 1000$ & $15 \& 30$ & Spatial resolution \\
\hline
\end{tabular}

\section{Surface energy balance on land (SEBAL) algorithm}

Theoretical basics of ET calculation using SEBAL method are provided in different references detailed. In this model, actual ET is calculated by using satellite images 
based on balance energy equation. Selected satellite images can only provide information about past time, so mentioned models are allowed possibility of estimating instantaneous latent heat flux in time imagery (Allen et al., 2007). Latent heat flux was calculated by using Equation 1 for each pixel of image.

$$
\lambda E T=R_{n}-H-G
$$

where $\lambda E T$ is latent heat flux $\left(\mathrm{W} / \mathrm{m}^{2}\right), R_{n}$ is net radiation flux on land surface $\left(\mathrm{W} / \mathrm{m}^{2}\right), \mathrm{G}$ is soil heat flux $\left(\mathrm{W} / \mathrm{m}^{2}\right)$ and $\mathrm{H}$ is sensible heat flux $\left(\mathrm{W} / \mathrm{m}^{2}\right)$. SEBAL method was presented first time in order to estimate ET in agricultural and plain areas. But it is corrected in new version (Allen et al., 2007) which is presented for application in rugged and mountainous areas. In the present study new version of SEBAL were used because of Malayer condition which has heterogeneous land use. Accuracy of latent heat flux estimation depends on calculation process and accuracy of $H, G$ and $R n$ estimation. The value of net radiation that is the first calculation to solve surface energy balance equation was calculated using Equation 2 and incoming and outgoing radiation fluxes (Allen et al., 2007).

$$
R_{n}=(1-\alpha) R_{S \downarrow}+R_{L \downarrow}-R_{L \uparrow}-\left(1-\varepsilon_{0}\right) R_{L \downarrow}
$$

where $R_{S \downarrow}$ is incoming short wave radiation $\left(\mathrm{W} / \mathrm{m}^{2}\right), \mathrm{R}_{\mathrm{L} \downarrow}$ is incoming long wave radiation ( $\left.\mathrm{w} / \mathrm{m}^{2}\right), \mathrm{R}_{\mathrm{L} \uparrow}$ is outgoing long wave radiation $\left(\mathrm{W} / \mathrm{m}^{2}\right), \alpha$ is surface albedo and $\varepsilon_{0}$ is surface radiation power of $31^{\text {th }}$ and $32^{\text {th }}$ MODIS bands and $10^{\text {th }}$ and $11^{\text {th }}$ Landsat 8 bands. Soil heat flux $(G)$ is the amount of heat transfer in soil and vegetation via molecular conduction. Since it is difficult to calculate the amount of soil heat flux using satellite image directly, so first $G / R_{n}$ ratio calculated in middle of the day using experimental equation (Bastiaanssen et al., 1998) (Eq. 3).

$$
\frac{G}{R_{n}}=\frac{T_{g}}{a}\left(0.0038 \alpha+0.0074 \alpha^{2}\right)\left(1-0.98 N D V I^{4}\right)
$$

where $T_{s}$ is surface temperature $\left({ }^{\circ} \mathrm{C}\right)$ and $\alpha$ is surface albedo. The $\mathrm{G}$ value was obtained by multiplying the above ratio in Rn. If NDVI value is less than 0 , then the area considered as water and $G / R_{n}$ ratio considered equal to 0.5 . The area having $T_{s}$ less than $4{ }^{\circ} \mathrm{C}$ and $\alpha$ more than 0.45 considered as snowy area and $\mathrm{G} / \mathrm{R}_{\mathrm{n}}$ ratio was applied equal to 0.5 . Sensible heat flux $(\mathrm{H})$ (the loss of heat to the air via molecular convection and conduction) is because of temperature difference which calculated using Equation 4 (Allen et al., 2007).

$$
H=\frac{\rho \cdot C P d T}{r_{\mathrm{anh}}}
$$

where $\rho$ is the air density $\left(\mathrm{kg} / \mathrm{m}^{3}\right), \mathrm{C}_{\mathrm{p}}$ is the specific heat of air $(1004 \mathrm{~J} / \mathrm{Kg} / \mathrm{K})$, dT is temperature difference $\left({ }^{\circ} \mathrm{K}\right)$ between two elevation $\left(Z_{1}-Z_{2}\right)$ and $r_{a h}$ is aerodynamic resistance against heat transmission $(\mathrm{s} / \mathrm{m})$. Sensible heat flux is a function of the temperature gradient, surface roughness and wind speed. Solving the above equation is difficult because of existence of two unknown parameters including $r_{a h}$ and $d T$ and therefore we used two cold and hot pixels of the study area (which reliable values are predictable for $\mathrm{H}$ and so present estimation of dT) and wind speed in the certain height. 
Regarding that $r_{\text {ah }}$ was a function of sensible heat flux, Equation 4 did not have explicit solution and it was solved based on cyclic method. In order to correct atmospheric stability Monin-Obukhov length was used. The cold pixel selected from an area covered with complete vegetation and irrigated completely based on mentioned instructions which it is assumed surface temperature equal to near surface temperature. As the same way, the hot pixel selected from an arid area without any vegetation which it is assumed ET is 0 . In selection of these pixels, some factors such as surface temperature, albedo and vegetation indices were used. That the cold pixel had low temperature, albedo of about 0.22 to 0.24 in accordance with alfalfa land and high NDVI, while hot pixel had high temperature, high albedo similar to other dry lands and without vegetation and low NDVI. In selection of hot/cold pixels, it considered to avoid very low or very high temperature selection. After correction of the sensible heat flux amount based on atmospheric condition, the instantaneous amount of latent heat flux calculated for each pixel of both images using Equation 1. Since the outcome amounts of net radiation flux $\left(R_{n}\right)$, sensible heat flux $(H)$ and soil heat flux $(G)$ were instantaneous amounts and for satellite pass time, the amount of latent heat flux $(\lambda \mathrm{ET})$ calculated instantaneous too. Therefore, ET amount was obtained from numerical calculation of $\lambda$ and by dividing the number of per-pixel. The amount of ET was obtained using instantaneous latent heat flux and Equation 5.

\section{Latent heat flux and instantaneous ET}

Latent heat flux is the amount of heat loss from surface due to ET process which was obtained using Equation 3. Since the amounts of net radiation flux $\left(\mathrm{R}_{\mathrm{n}}\right)$, sensible heat flux $(\mathrm{H})$ and soil heat flux $(\mathrm{G})$ are instantaneous amounts then the amount of latent heat flux $(\lambda \mathrm{ET})$ is momentary too. $\lambda \mathrm{ET}$ is the amount obtaining from satellite image. Therefore, we should calculate $\lambda$ numerical amount so the amount of ET is obtained by dividing the number of per-pixel.

The amount of ET is obtained using instantaneous latent heat flux as:

$$
E T_{\text {inst }}=3600 \frac{2 E T}{2}
$$

where $E T_{\text {inst }}$ is the amount of instantaneous ET $(\mathrm{mm} / \mathrm{hr}), \lambda$ is evaporation latenet heat $(\mathrm{J} / \mathrm{Kg})$ and 3600 number convert the time from seconds to hours. The amount of $\lambda$ is obtained using Equation 6.

$$
\lambda=\left[2.501-0.00236\left(T_{S}-273.15\right)\right] \times 10^{6}
$$

\section{Ratio of reference ET}

Ratio of reference ET is defined as ratio of instantaneous ET (ETinst) of each pixel $(\mathrm{mm} / \mathrm{hr})$ to reference ET (ETr) obtained from meteorological data for image time $(\mathrm{mm} / \mathrm{hr})(E q .7)$.

$$
E T_{r} F=\frac{E T_{\text {inst }}}{E T_{r}}
$$

$\mathrm{ET}_{\mathrm{r}} \mathrm{F}$ is similar to vegetation coefficient $(\mathrm{Kc})$ and used to extrapolate of ET from image time to $24 \mathrm{~h}$ period or much longer. The amount of $\mathrm{ET}_{\mathrm{r}} \mathrm{F}$ usually ranges between 
0 and 1 , so in a completely dry $\mathrm{ET}=0$ and $\mathrm{ET}_{\mathrm{r}} \mathrm{F}=0$, but in case of the cold pixel in an alfalfa or corn, ET is a few more than $\mathrm{ET}_{\mathrm{r}}$ and so $\mathrm{ET}_{\mathrm{r}} \mathrm{F}>1$ (1.1 likely). The negative amount for $\mathrm{ET}_{\mathrm{r}} \mathrm{F}$ is because of systematic errors which enter to SEBAL via various assumptions.

Various equations are developed to calculate $\mathrm{ET}_{\mathrm{r}}$, out of which, Penman-Montieth equation is proposed by FAO to most countries, such as Iran, having arid and semiarid climate. Penman-Montieth method has various versions; many of the researchers use FAO-Penman-Montieth version as one of the most reliable method for ET estimation (Alizade, 2002). Therefore, FAO-Penman-Montieth version 56 was used in REF-ET software for $\mathrm{ET}_{\mathrm{r}}$ calculation.

\section{4 hourly ET}

The daily amount of ET $\left(\mathrm{ET}_{24}\right)$ usually has more application than the instantaneous amount. SEBAL calculate $\mathrm{ET}_{24}$ amount assuming instantaneous $\mathrm{ET}_{\mathrm{r}} \mathrm{F}$ is similar to average $\mathrm{ET}_{\mathrm{r}} \mathrm{F}$ during $24 \mathrm{~h}$. The amount of $\mathrm{ET}_{\mathrm{r}} \mathrm{F}(\mathrm{mm} /$ day) is calculated as $(E q$. 8; Allen et al., 2007):

$$
E T_{24}=E T_{r} F \times E T_{r_{-} 24}
$$

where $\mathrm{ET}_{\mathrm{r} \_24}$ is sum of $\mathrm{ET}_{\mathrm{r}}$ during $24 \mathrm{~h}$ for the same day image recorded which is obtained by adding up the values of the hourly $\mathrm{ET}_{\mathrm{r}}$ together on the satellite pass day.

\section{Accuracy assessment}

Hourly and $24 \mathrm{~h}$ values of ETr obtained via FAO-Penman-Montieth method using hourly data of Malayer meteorological station was used to validate SEBAL model. Root Means Square Error and Mean Bias Error were used for statistical assessment of the models accuracy. The value of RMSE presents the amount of model error (Dashtaki et al., 2010). MBE index shows trend to overestimation or underestimation. Mathematical descriptions of these statistics are as follows (Eqs. 9 and 10):

$$
\begin{gathered}
\text { RMSE }=\sqrt{\frac{1}{n}} \sum_{i=1}^{n}\left(Y_{\text {est }}, i-Y_{o b s, i}\right)^{2} \\
M B E=\frac{1}{n} \sum_{i=1}^{n}\left(\text { Yest }_{,} i-\text { Yobs }_{i} i\right)
\end{gathered}
$$

where Yest is the projected amount, Yobs is the measurement amount and $n$ is the number of data.

\section{Results}

The maps of surface temperature distribution, vegetation index and daily ET are shown in Figure 2. Surface temperature and vegetation index are two important incomes to SEBAL model. These two indices, which are also applied to select hot/cold pixels, have a strong inverse correlation in case of accessing sufficient nutrient (Ruhoff et al., 2012). As shown in Figure 2, daily ET distribution shows a wide range of values regarding heterogeneous lands. Also, results show that an area which has high 
vegetation index (VI) and low temperature has more ET and vice versa. Based on the maps, there is an inverse correlation between surface temperature distribution and vegetation index.
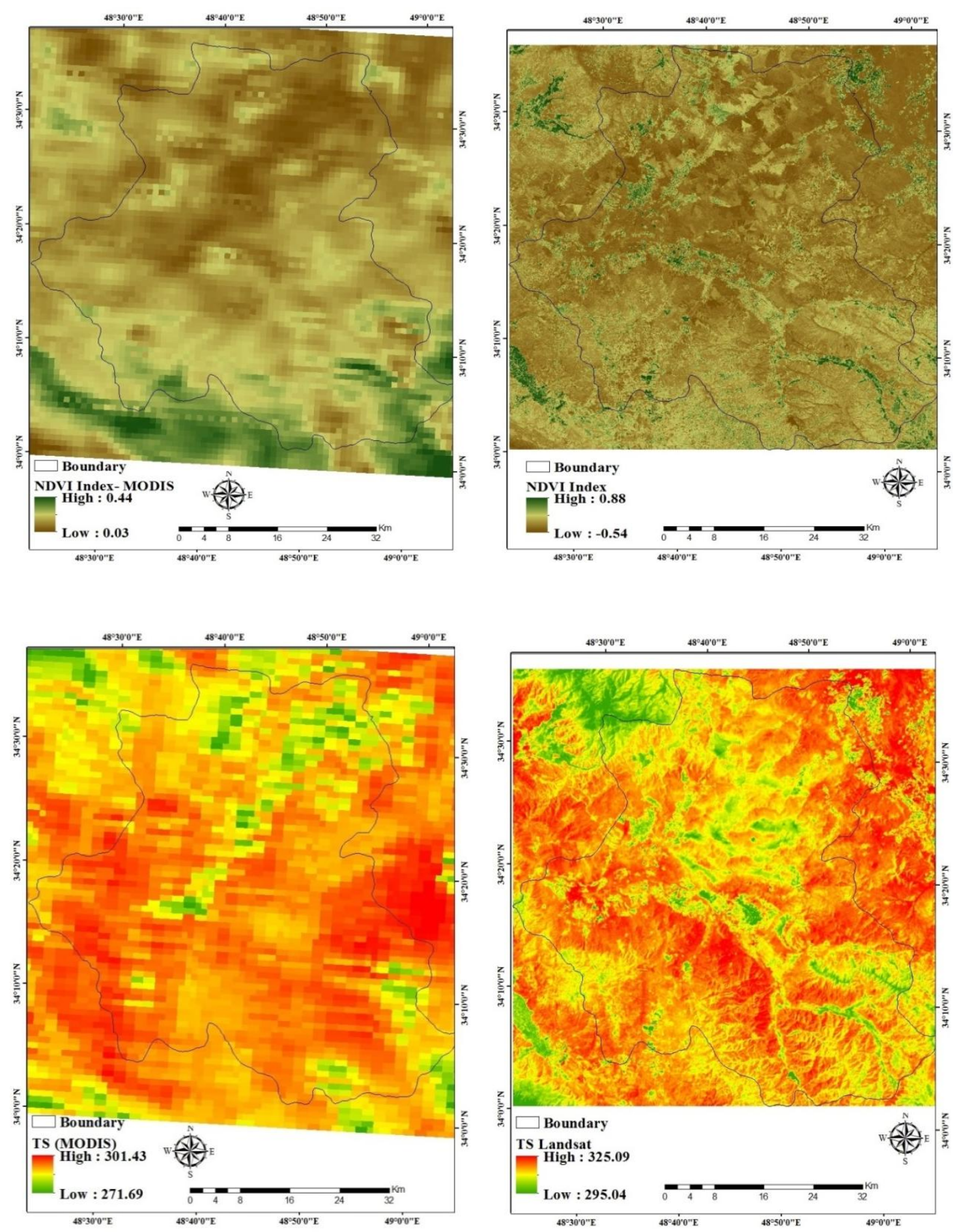

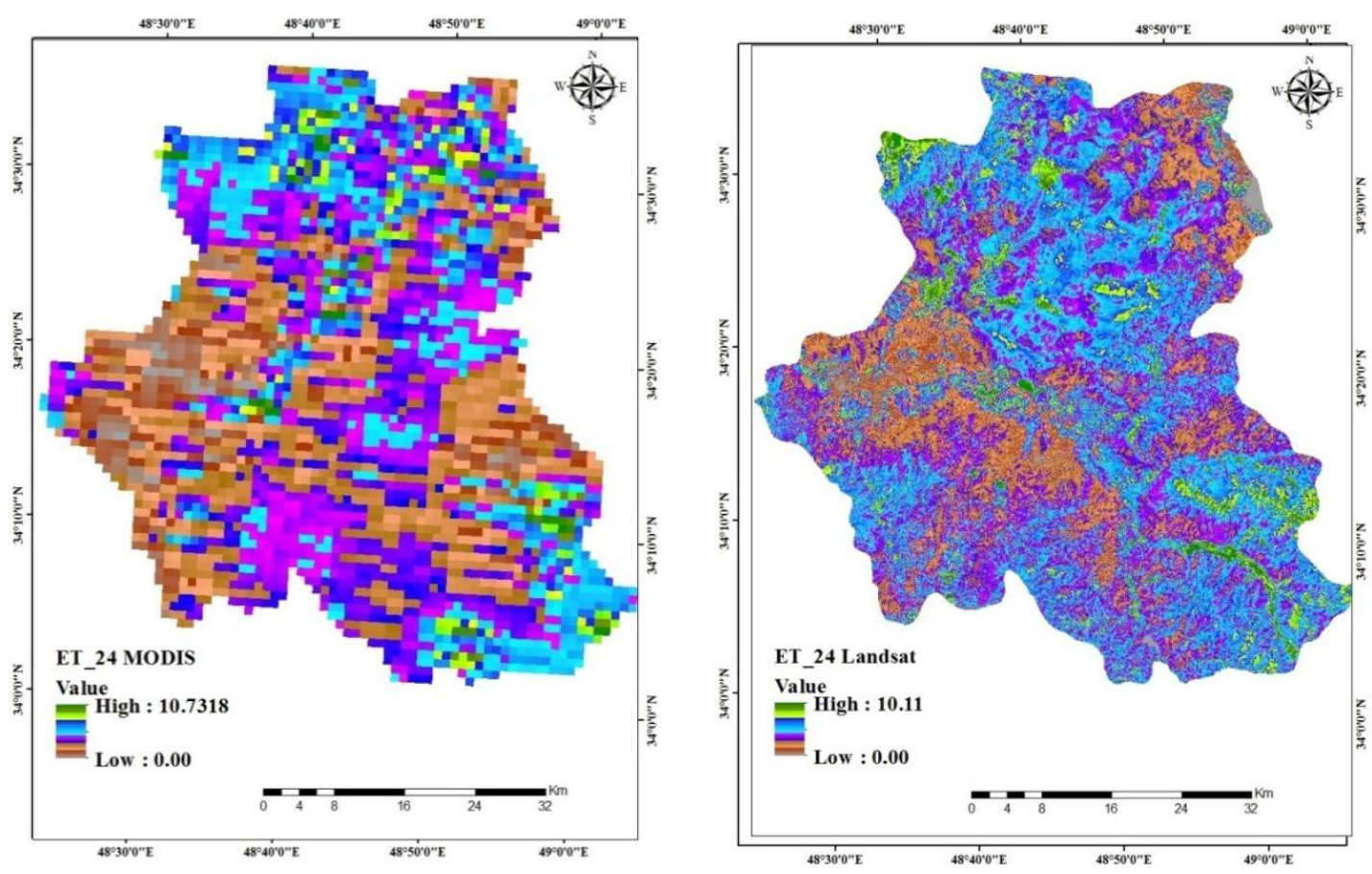

Figure 2. Top to bottom and left to right are: MODIS surface temperature, Landsat surface temperature, NDVI of MODIS, NDVI of Landsat, 24 hourly ET of MODIS, 24 hourly ET of Landsat respectively

\section{Actual ET estimation}

After calculating the net radiation flux $(\mathrm{Rn})$, sensible radiation flux $(\mathrm{H})$, soil heat flux (G) and latent heat flux of instantaneous evaporation, the amount of actual instantaneous ET (ETinst) was estimated.

The crop type and culture date were determined in desirable parts by using agriculture calendar. Then, the observed ET value of cultivated plants was estimated by using FAO-Penman-Montieth method and compared with results of SEBAL. The results of statistical comparison of SEBAL and FAO-Penman-Montieth are presented in Table 2 and Figure 3.

Table 2. Statistical comparison of SEBAL with FAO-Penman-Montieth (daily and hourly)

\begin{tabular}{|c|c|c|c|c|}
\hline Image & ET instant & ET ref instant & ET 24 & ET ref 24 \\
\hline MODIS & 0.7533 & 0.75 & 6.89 & 6.86 \\
\hline Landsat & 0.7888 & 0.75 & 7.23 & 6.86 \\
\hline
\end{tabular}

The ET amount measured by Landsat showed more differences with observed values. According to hourly ET measured through ETr software and calculated instantaneous values via satellite images showed MODIS accuracy is higher than Landsat with RMSE and MBE by 1.004 and 0.0033 respectively in comparison with Landsat with RMSE and ME by 1.05 and 2.88, respectively. But regarding images type and spatial resolution, it can be seen that accuracy of Landsat is much higher than MODIS image and it can interpolate the values of ET much better and clearer because 
of its smaller pixels. Ogawa et al. (1999) investigated performance of MODIS sensor in ET estimation in Savanah, West Africa. In that study, SEBAL method, MODIS and ASTER images were used. Their results showed both sensors have good capability to estimate ET in large heterogeneous areas and according to their results the present study has logical results in comparison with observed method. Sun et al. (2011) used SEBAL algorithm and Landsat image to estimate actual ET in various land uses in Nansi Lake Basin, China. These researchers reported positive results, similar to the present study which has emphasized on SEBAL capability in Malayer city.

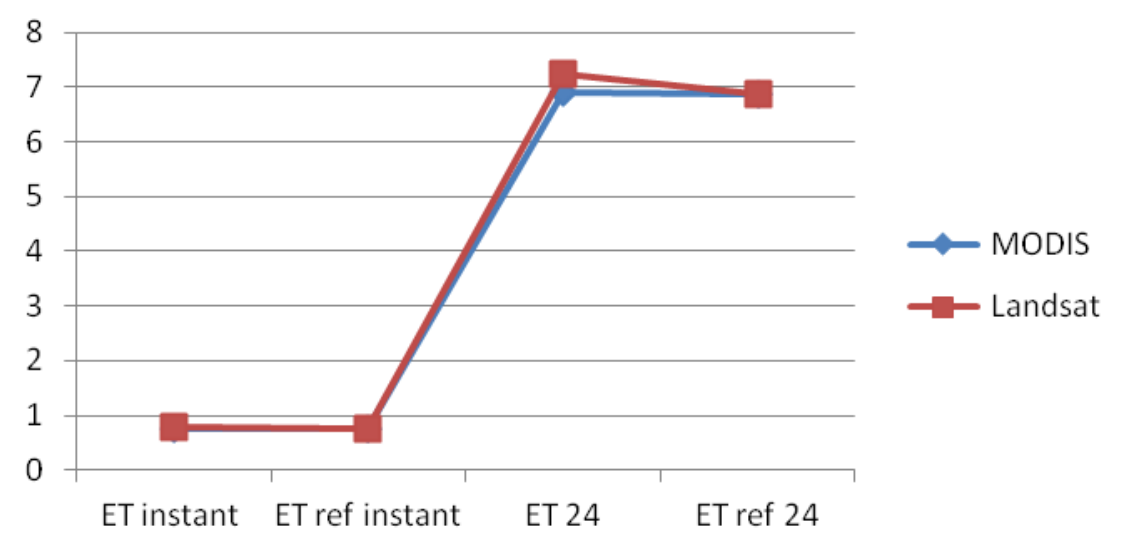

Figure 3. Plotting comparison of SEBAL with observed method (FAO-Penamn-Montieth)

According to assumption of SEBAL model based on Equation 8, daily ET was estimated. On the other hand, after correction of Kc based on proposed in FAO 56 leaflet for the study area and multiplied by observed ET of alfalfa which is obtained from meteorological data, daily actual ET values were estimated for desirable pixels. As shown in Table 2.

\section{Conclusion}

The greatest difference between SEBAL estimation and observed method is related to Landsat image. Based on daily ET obtained from ETr software, daily values that are calculated through satellite images and their statistical comparison, it is concluded that MODIS is more accurate than Landsat image and has less difference to observed ET. However, according to Figure 2 which shows daily ET and high spatial resolution of Landsat, precision of this image is much higher than MODIS image and it can show ET clearer and more suitably. According to SEBAL estimations despite the error which caused deviation and due to lack of needed equipment and image errors, it can be said that data obtained from this algorithm are acceptable.

The aim of this study was to estimate ET of vegetation by MODIS and Landsat 8 images. For this purpose, SEBAL algorithm was used. Besides, Malayer city does not have any lysimeter station so FAO-Penman-Montieth's results were used for accuracy assessment. Results showed SEBAL algorithm can estimate parameters such as surface albedo, surface temperature and vegetation index as well. Daily and hourly actual ET values were estimated in the study area by using mentioned parameters. Comparison of results from SEBAL algorithm and observed method (FAO-Penman-Montieth) did not show significant difference in either hourly or daily cases. It means hourly ET can be 
estimated with acceptable precision in comparison with observed ET in the study area. According to spatial resolution and free MODIS and Landsat images, it seems that the use of these images can be satisfactory and practical in order to estimate daily water requirement and plan for irrigation especially in wide lands.

The results of this study showed hourly estimations of ET through SEBAL algorithm have higher precision than daily estimations that is because of constant hourly ETref with daily ETref in model. Furthermore, comparison of estimating ET by two images which have different resolution made it clear that ET in MODIS image was estimated with higher accuracy for two anchor pixels (hot and cold pixels) than Landsat image. Nevertheless, according to observed ET, Landsat images had more accuracy due to higher spatial resolution and various heterogeneous land uses with low extent of study area.

\section{REFERENCES}

[1] Akbari, M. (2004): Improve the management of irrigation using a combination of satellite, farm and simulation model of SWAT. - Ph.D. Thesis, Tarbiat Modare University, Tehran.

[2] Alizadeh, A. (2002): Relationship of Water, soil, and vegetation- Ferdosi university of Mashhad, Iran.

[3] Allen, R. G., Pereira, L., Raes, D., Smith, M. (1998): FAO irrigation and drainage. Paper No. 56, pp. 26-40. - Food and Agriculture Organization of the United Nations, Rome.

[4] Allen, R. G., Tasumi, M., Trezza, R. (2007): Satellite-based energy balance for mapping evapotranspiration with internalized calibration (METRIC) model. - Journal of Irrigation and Drainage Engineering 133(4): 380-394.

[5] Bastiaanssen, W. G. M. (2000): SEBAL-based sensible and latent heat fluxes in the irrigated Gediz Basin, Turkey. - Journal of Hydrology 229(1-2): 87-100.

[6] Bastiaanssen, W. G. M., Menenti, M., Feddes, R. A., Holtslag, A. A. M. (1998): A remote sensing surface energy balance algorithm for land (SEBAL) - 1. Formulation. Journal Hydrol 1998(212-213): 198-212.

[7] Chavez, J. L., Gowda, P. H., Evett, S. R., Colaizzi, P. D., Howell, T. A., Marek, T. (2007): An application of METRIC for ET mapping in the Texas high plains - December 9-11, pp. 268-283. - Irrigation Association CD-ROM, San Diego.

[8] Colaizzi, P. D., Gowda, P. H., Marek, T. H., Paul, G., Howell, T. A. (2011): SEBAL for estimating hourly ET fluxes over irrigated and dryland cotton during BEAREX08, pp. 2787-2795. - World Environmental and Water Resources Congress 2011.

[9] Dashtaki, S. G., Homaee, M., Khodaverdiloo, H. (2010): Derivation and validation of pedo transfer functions for estimating soil water retention curve using a variety of soil data. - Soil Use and Management 26(1): 68-74.

[10] Dasturani, M. T., Pourmohammadi, S., Rahimian, M. H. (2012): Evapotranspiration estimation via remote sensing in Ardakan's pistachio gardens. - Journal of Water Research in Agriculture 26 (1): 1-12.

[11] Folhes, M. T., Renno, C. D., Soares, J. V. (2009): Remote sensing for irrigation water management in the semi-arid Northeast of Brazil. - Agricultural Water Management 96: 1398-1408.

[12] Hargreaves, G. H. (1994): Defining and using reference evapotranspiration. - Journal of Irrigation and Drainage Engineering 120(6): 1132-1139.

[13] Hasheminia, M. (1999): Evaporation, Evapotranspiration and Climatical Data. Agricultural Education Publishing, Karaj, Tehran. 
[14] Huntingford, C., Verhoef, A., Stewart, J. (2000): Dual versus single source models for estimating surface temperature of African savannah. - Hydrology and Earth System Sciences Discussions 4(1): 185-191.

[15] Li, F., Lyons, T.J. (1999): Estimation of regional evapotranspiration through remote sensing- Journal of Applied Meteorology. 38, 1644-1654.

[16] Li, F., Lyons, T. J. (2002): Remote estimation of regional evapotranspiration. Environmental Modelling and Software 17: 61-75.

[17] Mutiga, J., Su, Z., Woldai, T. (2010): Using satellite remote sensing to assess evapotranspiration: Case study of the upper Ewaso Ng'iro North Basin, Kenya. International Journal of Applied Earth Observation and Geoinformation 12(S1): s100s108.

[18] Nishida, K., Nemani, R. R., Running, S. W., Glassy, J. M. (2003): An operational remote sensing algorithm of land surface evaporation. - Journal of Geophysical Research 108(D9): 4270.

[19] Norman, J. M., Kustas, W. P., Humes, K. S. ( 1995): Source approach for estimating soil and vegetation energy fluxes in observations of directional radiometric surface temperature. - Agricultural and Forest Meteorology 77(3): 263-293.

[20] Ogawa, S., Murakaml, T., Ishitsuka, N., Saito, G., (1999): Evapotranspiration Estimates from Fine-Resolution NDVI. - National Institute of Agro-Environmental Science (Japan).

[21] Paul, G., Gowda, P. H., Vara Prasad, P. V., Howell, T. A., Staggenborg, S. A., Neale, C. M. U. (2013): Lysimetric evaluation of SEBAL using high resolution airborne imagery from BEAREX08. - Advances in Water Resources 59:157-168.

[22] Raghuveer K. V., Eric, F. W., Craig, R. F., Joshua, B. F. (2011): Global estimates of evapotranspiration for climate studies using multi-sensor remote sensing data: Evaluation of three process-based approaches. - Remote Sensing of Environment 115: 801-823.

[23] Ruhoff, A. L., Paz, A. R., Collischonn, W., Aragao L. E. O. C., Rocha, H. R., Malhi, Y. S. (2012): A MODIS-based energy balance to estimate evapotranspiration for clear-sky days in Brazilian tropical savannas. - Journal of Remote Sensing 4: 703-725.

[24] Sánchez, J., Kustas, W., Caselles, V., Anderson, M. (2008): Modelling surface energy fluxes over maize using a two-source patch model and radiometric soil and canopy temperature observations. - Remote Sensing of Environment 112(3): 1130-1143.

[25] Sepaskhah, A.R. (1982): Rainfall assembly in the plain of iran, final report, number AG298 -18- Agriculture university of Shiraz, Iran.

[26] Simaie, E., Homaie, M., Norouzi, A. A. (2013): Evaluation of SEBAL model in evapotranspiration estimate using TM and MODIS data. - Journal of Soil and Water Resources Protection 2(4): 33-39.

[27] Song, C., Woodcock, C. E., Seto, K. C., Lenney, M. P., Macomber, S. A. (2001): Classification and change detection using Landsat TM data: when and how to correct atmospheric effect. - Remote Sensing of Environment 75: 230-244.

[28] Su, Z. (2002): The Surface Energy Balance System (SEBS) for estimation of turbulent heat fluxes. - Hydrology and Earth System Sciences Discussions 6(1): 85-100.

[29] Sun, Z., Wei, B., Su, W., Shen, W., Wang, C., You, D., Liu, Z. (2011): Evapotranspiration estimation based on the SEBAL model in the Nansi Lake Wetland of China. - Mathematical and Computer Modelling 54(3-4): 1086-1092.

[30] Tasumi, M., Trezza, R., Allen, R. G., Wright, J. L. (2005): Operational aspects of satellite-based energy balance models for irrigated crops in the semi-arid US. - Irrigation and Drainage Systems 19(3): 355-376.

[31] Yuting, Y., Songhao, S., Lei, J. (2012): Remote sensing temporal and spatial patterns of evapotranspiration and the responses to water management in a large irrigation district of North China. - Agricultural and Forest Meteorology 164: 112-122. 